\title{
Incidence and survival of childhood bone cancer in northern England and the West Midlands, 198I-2002
}

\author{
R Eyre', RG Feltbower², E Mubwandarikwa', HC Jenkinson ${ }^{3}$, S Parkes $^{3}$, JM Birch $^{4}$, TOB Eden $^{5}$, PW James', \\ PA McKinney², MS Pearce' and RJQ McNally*,I
}

'Institute of Health and Society, Newcastle University, Newcastle upon Tyne NEI 4LP, UK; ${ }^{2}$ Paediatric Epidemiology Group, Centre for Epidemiology and Biostatistics, University of Leeds, Leeds LS2 9JT, UK; ${ }^{3}$ West Midlands Regional Children's Tumour Registry, Birmingham Children's Hospital, Birmingham B4 6NH, UK; ${ }^{4}$ Cancer Research UK Paediatric and Familial Cancer Research Group, University of Manchester, Manchester M27 4HA, UK; ${ }^{5}$ Academic Unit of Paediatric and Adolescent Oncology, clo Teenage Cancer Trust Young Oncology Unit, Christie Hospital, University of Manchester, Manchester M20 4BX, UK

There is a paucity of population-based studies examining incidence and survival trends in childhood bone tumours. We used high quality data from four population-based registries in England. Incidence patterns and trends were described using Poisson regression. Survival trends were analysed using Cox regression. There were 374 cases of childhood (ages 0-14 years) bone tumours (206 osteosarcomas, 144 Ewing sarcomas, 16 chondrosarcomas, 8 other bone tumours) registered in the period 1981-2002. Overall incidence (per million person years) rates were 2.63 (95\% confidence interval (Cl) 2.27-2.99) for osteosarcoma, I.90 (I.58-2.2I) for Ewing sarcoma and 0.21 ( 0.1 I - 0.31 ) for chondrosarcoma. Incidence of Ewing sarcoma declined at an average rate of 3.1\% (95\% Cl 0.6-5.6) per annum $(P=0.04)$, which may be due to tumour reclassification, but there was no change in osteosarcoma incidence. Survival showed marked improvement over the 20 years ( $198 \mathrm{I}-2000)$ for Ewing sarcoma (hazard ratio (HR) per annum $=0.9595 \%$ $\mathrm{Cl} 0.9 \mathrm{I}-0.99 ; P=0.02$ ). However, no improvement was seen for osteosarcoma patients (HR per annum $=1.0295 \% \mathrm{Cl} 0.98-1.05$; $P=0.35)$ over this time period. Reasons for failure to improve survival including potential delays in diagnosis, accrual to trials, adherence to therapy and lack of improvement in treatment strategies all need to be considered. British Journal of Cancer (2009) 1 00, I88-193. doi:I0.1038/sj.bjc.6604837 www.bjcancer.com (c) 2009 Cancer Research UK

Keywords: bone cancer; children; Ewing sarcoma; incidence; osteosarcoma; survival

\begin{abstract}
Malignant bone tumours are the seventh most common group of malignancies in children, comprising around $3-5 \%$ of cancers at ages 0-14 years (Parkin et al, 1998) with an age standardised incidence of approximately 5 per million person years in the United Kingdom (Stiller, 2007). The majority of these tumours are osteosarcoma or Ewing sarcoma (Stiller et al, 2006a), in the United Kingdom 54\% being osteosarcoma, 39\% Ewing sarcoma, 2\% chondrosarcoma and 5\% other types (Stiller, 2007). Worldwide, trends in incidence rates for childhood bone tumours have remained constant (McNally et al, 2001; Stiller et al, 2006a; Magnanti et al, 2008), although a few studies have reported increases (Ajiki et al, 1994; Gurney et al, 1996). The substantial improvement in survival over the past 40 years (Arndt et al, 2007) has been attributed to chemotherapy (Stiller et al, 2006a). Among European countries (19 countries), 5-year survival for all childhood bone tumours improved from $37 \%$ in $1978-1982$ to $63 \%$ in 1993-1997. For osteosarcoma and Ewing sarcoma, 5-year survival also improved
\end{abstract}

*Correspondence: Dr RJQ McNally, Sir James Spence Institute, Newcastle University, Royal Victoria Infirmary, Queen Victoria Road, Newcastle upon Tyne NEI 4LP, UK;

E-mail: Richard. McNally@ncl.ac.uk

Received 8 August 2008; revised 21 November 2008; accepted 24 November 2008 from 37 to $61 \%$ and from 34 to $66 \%$, respectively over this period (Stiller et al, 2006a). We describe the incidence and survival from bone tumours at ages 0-14 years in northern England and the West Midlands during the period 1981-2002, updating previous analyses (Cotterill et al, 2000; Stiller et al, 2006c).

\section{MATERIALS AND METHODS}

Data were included for all children registered during the period 1981-2002 by the Northern Region Young Persons' Malignant Disease Registry (NRYPMDR), the Yorkshire Specialist Register of Cancer in Children and Young People (YSRCCYP), the West Midlands Regional Children's Tumour Registry (WMRCTR) and the Manchester Children's Tumour Registry (MCTR). These are specialist registries that record cases of cancer in children and young adults, and together cover around $35 \%$ of the 0 - to 14 -yearold population in England (2001 combined census population for 0-14 year olds approximately 3250000 ) (Figure 1). All four registries are population based and have very high levels of ascertainment due to rigorous data collection procedures. Methods of follow-up vary according to the individual registries. At the NRYPMDR, children are actively followed up through general practitioners and hospital records. At the YSRCCYP, children are actively followed up through general practitioners and hospital records every 2 years to determine health status, treatment and 


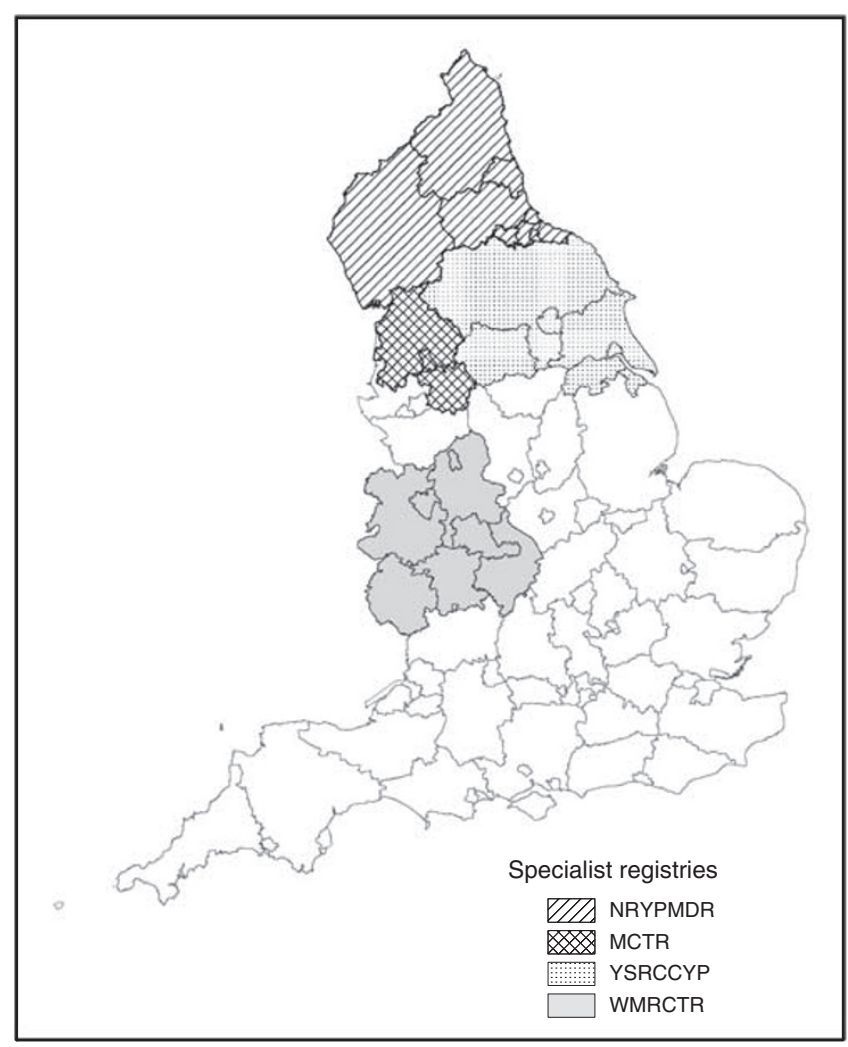

Figure I Geographical areas covered by the specialist registries.

adverse outcomes such as second malignancies or relapse. Crosschecks with the national clinical trial databases are undertaken to ensure trial entry status is complete. At the WMRCTR, follow-up methods are both clinical and postal: surviving patients are seen annually or every 2 years in clinic, and those who do not attend have a postal questionnaire sent to their GP every 3 years. At the MCTR, for the first 35 years (1954-late 1980s) active follow-up was carried out by writing to hospitals, GPs and, in some instances, patients or their parents. The MCTR also received discharge summaries from the Christie Hospital and Royal Manchester Children's Hospital. From the 1980s onwards, active follow-up was ceased as cases were flagged at the National Health Service Central Register (NHSCR) and they continue to receive discharge summaries and follow-up clinic letters from the two main hospitals. The percentage of cases lost to follow-up are as follows: NRYPMDR $0.72 \%$, YSRCCYP less than $0.5 \%$, WMRCTR $4.2 \%$ (although tracing through the NHS Strategic Tracing Service has not revealed any deaths in this group), MCTR less than $10 \%$ (Birch, 1988; Muir et al, 1992; Cotterill et al, 2000; Feltbower et al, 2007).

Malignant bone tumours were defined as all those neoplasms in group VIII of the International Classification of Childhood Cancer (ICCC) (Steliarova-Foucher et al, 2005). Primary malignant bone tumours registered between 1981 and 2002 in patients aged $0-14$ years at the time of diagnosis were extracted from the four participating English cancer registries. The diagnostic subgroups included osteosarcomas (ICCC subgroup VIIIa), chondrosarcomas (ICCC subgroup VIIIb), Ewing sarcomas (ICCC subgroup VIIIc), specified malignant tumours (ICCC subgroup VIIId) and unspecified malignant tumours (ICCC subgroup VIIIe). Secondary and benign bone tumours were excluded from this study. Information available for each case included demographic data (gender, date of birth), information on the tumour (diagnosis date, site and for NRYPMDR only, stage) and information on follow-up (current status, date of death, date of last follow-up).

\section{Statistical analysis}

Age-specific incidence rates per million person years were calculated based on mid-year population estimates for the study region obtained from Office for National Statistics. Age-standardised incidence rates (ASR) were calculated based on the standard world population (Smith, 1992). Poisson regression models were used to assess the effects on incidence rate of time period for diagnosis (1981-1988,1989-1995, 1996-2002), age group (0-4, $5-9,10-14)$, gender and registry. Regression coefficients and corresponding 95\% confidence intervals (CIs) are reported. Fiveyear survival rates were calculated for all cases diagnosed between 1981 and 2000, as follow-up was only available for all cases until the end of 2005. Survival rates were calculated using Kaplan-Meier estimation (Kaplan and Meier, 1958) and the differences in survival between diagnostic groups were assessed using log-rank tests. Cox Proportional Hazards regression analysis was used to model the probability of survival in relation to age, gender and year of diagnosis. Statistical significance was taken to be $P<0.05$ in all analyses. All statistical analyses were performed using Stata version 10

\section{RESULTS}

There were 374 patients aged 0-14 years diagnosed with a malignant bone tumour in the study region between 1981 and 2002. The ASR over the study period was 4.84 per million for all $0-14$ year olds. The number of cases and age-specific incidence rates by gender and disease type are shown in Table 1 . There was no statistical evidence for any gender differences in total bone tumour incidence or within any of the bone tumour subgroups. The most common malignant bone tumours diagnosed were osteosarcoma (206 cases) and Ewing sarcoma (144 cases). These comprised 55.1 and $38.5 \%$ of diagnoses, respectively. Other subgroups were diagnosed in smaller numbers, with 16 chondrosarcoma cases $(4.3 \%$ of diagnoses) and 8 other bone tumours (2.1\%). Age-standardised incidence rates per million population years for each of the bone tumour subgroups were 2.63 (95\% CI 2.27-2.99) for osteosarcoma, 0.21 (95\% CI $0.11-0.31)$ for chondrosarcoma, 1.90 (95\% CI 1.58-2.21) for Ewing sarcoma and 0.10 (95\% CI $0.04-0.20)$ for the group comprising other specified and unspecified tumours.

Bone cancer incidence was not uniform across age groups (Table 1). Poisson regression models showed that after adjustment for gender and time period, incidence was highest at age 10-14 years. The incidence rate ratios (IRRs) for age group 10-14 years relative to $0-4$ years were 13.21 (95\% CI 6.48-26.94) for osteosarcoma; 2.88 (95\% CI 1.05-7.93) for chondrosarcoma; 3.76 (95\% CI 2.23-6.33) for Ewing sarcoma and 5.19 (95\% CI 1.0525.70) for other bone tumours. Incidence rates were also higher in the age group 5-9 years than 0-4 years for osteosarcoma and Ewing sarcoma. The IRRs for age group 5-9 years relative to 0-4 years were 5.96 (95\% CI: $2.85-12.47)$ for osteosarcoma and 2.03 (95\% CI: 1.16-3.55) for Ewing sarcoma.

Incidence did not differ between males and females for osteosarcoma $(P=0.14)$, chondrosarcoma $(P=0.37)$, Ewing sarcoma $(P=0.98)$ or other bone tumours $(P=0.94)$. Incidence rates were also similar in all four registries.

The results of the analyses of time trends in bone tumour incidence during 1981-2002 are shown in Table 2. After adjustment for age and gender, there was evidence that the incidence rate for Ewing sarcoma decreased on average by $3.1 \%$ (95\% CI $0.6-5.6)$ each year $(P=0.04)$. This rate of decline was not affected by gender $(P=0.64)$. There was no evidence of any change 
Table I Number of cases and incidence rates per million per year by diagnostic group, gender and age- group, 1981-2002

\begin{tabular}{|c|c|c|c|c|c|c|c|c|}
\hline \multirow[b]{2}{*}{ Diagnostic group } & \multirow[b]{2}{*}{ Gender } & \multicolumn{2}{|c|}{ Age 0-4 years } & \multicolumn{2}{|c|}{ Age 5-9 years } & \multicolumn{2}{|c|}{ Age $10-14$ years } & \multirow{2}{*}{$\frac{\text { Age } 0-14 \text { years }}{\text { ASR }(95 \% \mathrm{Cl})}$} \\
\hline & & $\mathbf{N}$ & Rate $(95 \% \mathrm{Cl})$ & $N$ & Rate $(95 \% \mathrm{Cl})$ & $\mathbf{N}$ & Rate $(95 \% \mathrm{Cl})$ & \\
\hline & Male & 15 & $1.59(0.78,2.39)$ & 52 & $4.38(3.19,5.56)$ & 116 & $9.39(7.68,11.10)$ & $4.63(3.96,5.31)$ \\
\hline & Female & 13 & $1.44(0.66,2.23)$ & 56 & $4.95(3.65,6.25)$ & 122 & $10.40(8.56,12.25)$ & $5.06(4.34,5.79)$ \\
\hline \multirow[t]{2}{*}{ Osteosarcoma } & All persons & 8 & $0.43(0.13,0.73)$ & 60 & $2.59(1.93,3.24)$ & 138 & $5.73(4.78,6.69)$ & $2.63(2.27,2.99)$ \\
\hline & Male & 4 & $0.42(0.01,0.84)$ & 26 & $2.19(1.35,3.03)$ & 65 & $5.26(3.98,6.54)$ & $2.37(1.89,2.84)$ \\
\hline & Male & 2 & $0.21(0.03,0.77)$ & 2 & $0.17(0.02,0.61)$ & 6 & $0.49(0.18,1.06)$ & $0.26(0.10,0.42)$ \\
\hline & Female & 0 & $0.00(0.00,0.00)$ & 2 & $0.18(0.02,0.64)$ & 4 & $0.34(0.09,0.87)$ & $0.16(0.06,0.34)$ \\
\hline \multirow[t]{3}{*}{ Ewing sarcoma } & All persons & 17 & $0.92(0.48,1.36)$ & 43 & $1.85(1.30,2.41)$ & 84 & $3.49(2.74,4.23)$ & $1.90(1.58,2.21)$ \\
\hline & Male & 9 & $0.95(0.33,1.58)$ & 24 & $2.02(1.21,2.83)$ & 41 & $3.32(2.30,4.34)$ & $1.91(1.47,2.35)$ \\
\hline & Female & 8 & $0.89(0.27,1.51)$ & 19 & $1.68(0.92,2.43)$ & 43 & $3.67(2.57,4.76)$ & $1.88(1.44,2.33)$ \\
\hline \multirow[t]{2}{*}{ Other ${ }^{b}$} & All persons & I & $0.05(0.00,0.30)$ & । & $0.04(0.00,0.24)$ & 6 & $0.25(0.09,0.54)$ & $0.10(0.04,0.20)$ \\
\hline & Male & 0 & $0.00(0.00,0.00)$ & 0 & $0.00(0.00,0.00)$ & 4 & $0.32(0.09,0.83)$ & $0.09(0.03,0.24)$ \\
\hline
\end{tabular}

$\mathrm{ASR}=$ age-standardised incidence rates; $\mathrm{Cl}=$ confidence interval. ${ }^{\mathrm{a}}$ Rates data include $95 \% \mathrm{Cl}$ in parentheses. ${ }^{\mathrm{b}}$ Other specified and unspecified tumours.

Table 2 Number of cases and ASR's per million per year by diagnostic group and time periods, $|98|-2002^{2}$

\begin{tabular}{|c|c|c|c|c|c|c|c|}
\hline \multirow[b]{2}{*}{ Diagnostic group } & \multirow[b]{2}{*}{ Gender } & \multicolumn{2}{|c|}{$|98|-\mid 988$} & \multicolumn{2}{|c|}{ | $989-1995$} & \multicolumn{2}{|c|}{$1996-2002$} \\
\hline & & $\mathbf{N}$ & Rate $(95 \% \mathrm{CI})$ & $\mathbf{N}$ & Rate $(95 \% \mathrm{CI})$ & $\mathbf{N}$ & Rate $(95 \% \mathrm{Cl})$ \\
\hline \multirow[t]{3}{*}{ All types } & All persons & 149 & $5.29(4.43,6.15)$ & 126 & $5.41(4.46,6.35)$ & 99 & $3.82(3.07,4.58)$ \\
\hline & Male & 66 & $4.58(3.46,5.70)$ & 67 & $5.61(4.26,6.95)$ & 50 & $3.80(2.74,4.86)$ \\
\hline & Female & 83 & $6.05(4.73,7.36)$ & 59 & $5.20(3.87,6.53)$ & 49 & $3.85(2.77,4.93)$ \\
\hline \multirow[t]{3}{*}{ Osteosarcoma } & All persons & 75 & $2.59(2.00,3.18)$ & 73 & $3.11(2.39,3.82)$ & 58 & $2.24(1.66,2.82)$ \\
\hline & Male & 33 & $2.21(1.45,2.97)$ & 33 & $2.73(1.80,3.67)$ & 29 & $2.20(1.39,3.00)$ \\
\hline & Female & 42 & $2.98(2.07,3.89)$ & 40 & $3.50(2.42,4.59)$ & 29 & $2.28(1.45,3.11)$ \\
\hline \multirow[t]{3}{*}{ Chondrosarcoma } & All persons & 7 & $0.28(0.11,0.58)$ & 3 & $0.13(0.03,0.37)$ & 6 & $0.22(0.08,0.48)$ \\
\hline & Male & 3 & $0.26(0.05,0.77)$ & 3 & $0.25(0.05,0.72)$ & 4 & $0.29(0.08,0.73)$ \\
\hline & Female & 4 & $0.30(0.08,0.77)$ & 0 & $0.00(0.00,0.00)$ & 2 & $0.15(0.02,0.54)$ \\
\hline \multirow[t]{3}{*}{ Ewing sarcoma } & All persons & 63 & $2.27(1.71,2.84)$ & 49 & $2.13(1.53,2.73)$ & 32 & $1.26(0.82,1.69)$ \\
\hline & Male & 28 & $1.98(1.24,2.72)$ & 30 & $2.55(1.63,3.46)$ & 16 & $1.24(0.63,1.86)$ \\
\hline & Female & 35 & $2.58(1.72,3.45)$ & 19 & $1.70(0.93,2.46)$ & 16 & $1.27(0.64,1.89)$ \\
\hline \multirow[t]{3}{*}{ Other $^{b}$} & All persons & 4 & $0.15(0.04,0.39)$ & 1 & $0.04(0.00,0.23)$ & 3 & $0.11(0.02,0.32)$ \\
\hline & Male & 2 & $0.12(0.01,0.45)$ & 1 & $0.08(0.00,0.45)$ & 1 & $0.07(0.00,0.40)$ \\
\hline & Female & 2 & $0.18(0.02,0.65)$ & 0 & $0.00(0.00,0.00)$ & 2 & $0.15(0.02,0.54)$ \\
\hline
\end{tabular}

$\mathrm{ASR}=$ age-standardised incidence rates; $\mathrm{Cl}=$ confidence interval. ${ }^{a}$ Rates data include $95 \% \mathrm{Cl}$ in parentheses. ${ }^{\mathrm{b}}$ Other specified and unspecified tumours.

over time for osteosarcoma $(P=0.64)$, chondrosarcoma $(P=0.72)$ or other bone tumours $(P=0.79)$.

Five-year survival rates by period of diagnosis by bone tumour subgroup are shown in Table 3. In total, $57.8 \%$ (95\% CI 52.5-63.0) of $0-14$ year olds diagnosed in the study region during $1981-2000$ survived for at least 5 years from the date of diagnosis. The 5-year survival rates for the bone tumour subgroups are respectively $58.8 \%$ (95\% CI 51.8 -65.9) for osteosarcoma, 53.3\% (95\% CI 26.678.8) for chondrosarcoma, 54.9\% (95\% CI 46.4-63.3) for Ewing sarcoma and $100 \%$ for other bone tumours. We found no difference in survival rate between diagnostic groups (log-rank test: $P=0.85$ ) (Figure 2).

A Cox Proportional Hazards regression model for survival showed that for Ewing sarcoma the risk of death was higher for cases aged 10-14 years than for those aged 0-9 years (hazard ratio $(\mathrm{HR})=1.8695 \%$ CI $1.12-3.07 ; P=0.02$ ) (Figure 3 ). After adjusting the model for age, the risk of death decreased by $5 \%$ for each year of the study period ( $\mathrm{HR}=0.9595 \%$ CI $0.91-0.99 ; P=0.02$ ). Survival rates were similar for male and female Ewing sarcoma patients
$(P=0.79)$. The analysis of 5-year survival rates over the study period for Ewing sarcoma shows when improvement occurred (overall survival $37.5 \%$ of cases diagnosed in 1981-1987, 95\% CI $24.8-50.1 ; 66.0 \%$ for $1988-1994,95 \%$ CI $52.4-79.5$; and $70.0 \%$ for cases diagnosed in 1995-2000, 95\% CI 53.6-86.4) (Table 3).

For osteosarcoma, there was no evidence that gender $(P=0.54)$, age $(P=0.45)$ or year of diagnosis $(P=0.35)$ had any effect on survival.

For chondrosarcoma, neither gender $(P=0.23)$ nor age $(P=0.16)$ had any effect on survival. There was marginally significant evidence that year of diagnosis had an effect on survival for chondrosarcoma, with risk of death decreasing by $10 \%$ for each year of the study period $(\mathrm{HR}=0.90,95 \% \mathrm{CI}$ : $0.80-1.02$; $P=0.09$ ).

There was no evidence that disease site had any effect on survival when lower limbs were compared with all other sites (osteosarcoma $P=0.52$; chondrosarcoma $P=0.71$; Ewing sarcoma $P=0.43$ ). As stage was only available from the NRYPMDR, there were too few patients for any further analyses to be conducted on survival by stage. 
Table 3 Percentage 5-year survival by time period, diagnostic group and age

\begin{tabular}{|c|c|c|c|c|}
\hline Diagnostic group & Gender & $\begin{array}{c}|98|-\mid 987 \\
\text { Rate }(95 \% \mathrm{Cl})\end{array}$ & $\begin{array}{c}1988-1994 \\
\text { Rate }(95 \% \mathrm{Cl})\end{array}$ & $\begin{array}{c}1995-2000 \\
\text { Rate }(95 \% \mathrm{Cl})\end{array}$ \\
\hline All types & $\begin{array}{l}\text { All persons } \\
\text { Male } \\
\text { Female }\end{array}$ & $\begin{array}{l}51.13(42.63,59.62) \\
57.14(44.18,70.10) \\
46.75(35.61,57.90)\end{array}$ & $\begin{array}{l}61.74(52.86,70.62) \\
59.70(47.96,71.45) \\
64.58(51.05,78.11)\end{array}$ & $\begin{array}{l}62.37(52.52,72.21) \\
61.90(47.22,76.59) \\
62.75(49.48,76.01)\end{array}$ \\
\hline Osteosarcoma & $\begin{array}{l}\text { All persons } \\
\text { Male } \\
\text { Female }\end{array}$ & $\begin{array}{l}60.61(48.82,72.39) \\
68.97(52.13,85.80) \\
54.05(38.00,70.11)\end{array}$ & $\begin{array}{l}58.46(46.48,70.44) \\
58.06(40.69,75.44) \\
58.82(42.28,75.37)\end{array}$ & $\begin{array}{l}57.14(44.18,70.10) \\
54.17(34.23,74.10) \\
59.38(42.36,76.39)\end{array}$ \\
\hline Chondrosarcoma & $\begin{array}{l}\text { All persons } \\
\text { Male } \\
\text { Female }\end{array}$ & $\begin{array}{l}42.86(9.90,81.59) \\
66.67(9.43,99.16) \\
25.00(0.63,80.59)\end{array}$ & $\begin{array}{l}50.00(1.26,98.74) \\
50.00(1.26,98.74) \\
0.00(-)\end{array}$ & $\begin{array}{l}67.00(22.28,95.67) \\
75.00(19.41,99.16) \\
50.00(1.26,98.74)\end{array}$ \\
\hline Ewing sarcoma & $\begin{array}{l}\text { All persons } \\
\text { Male } \\
\text { Female }\end{array}$ & $\begin{array}{l}37.50(24.82,50.18) \\
36.36(16.26,56.47) \\
38.24(21.90,54.57)\end{array}$ & $\begin{array}{l}65.96(52.41,79.50) \\
60.61(43.93,77.28) \\
78.57(49.20,95.34)\end{array}$ & $\begin{array}{l}70.00(53.60,86.40) \\
71.43(47.76,95.09) \\
68.75(46.04,91.46)\end{array}$ \\
\hline
\end{tabular}

$\mathrm{Cl}=$ confidence interval. ${ }^{\text {a }}$ Rates data include $95 \% \mathrm{Cl}$ in parentheses. ${ }^{\mathrm{b}}$ Other specified and unspecified tumours.

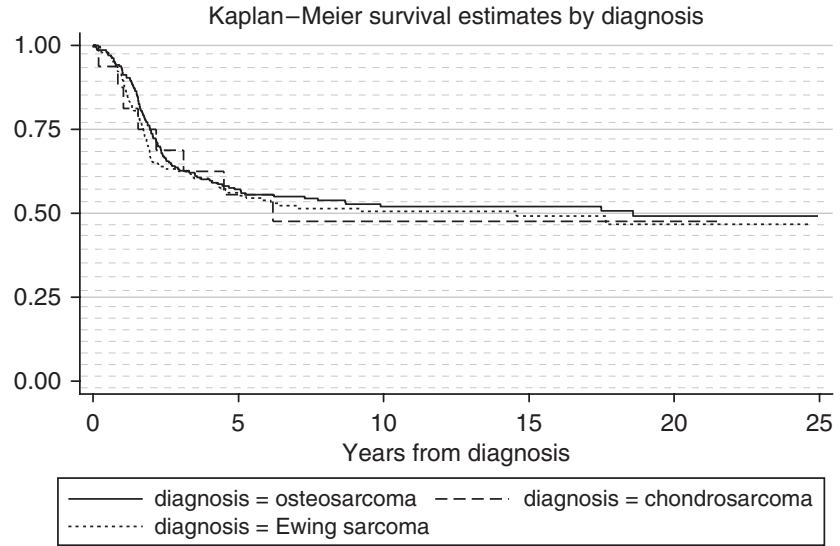

Figure 2 Kaplan-Meier survival by diagnosis group. Log-rank test for differences between diagnostic groups; $P=0.85$.

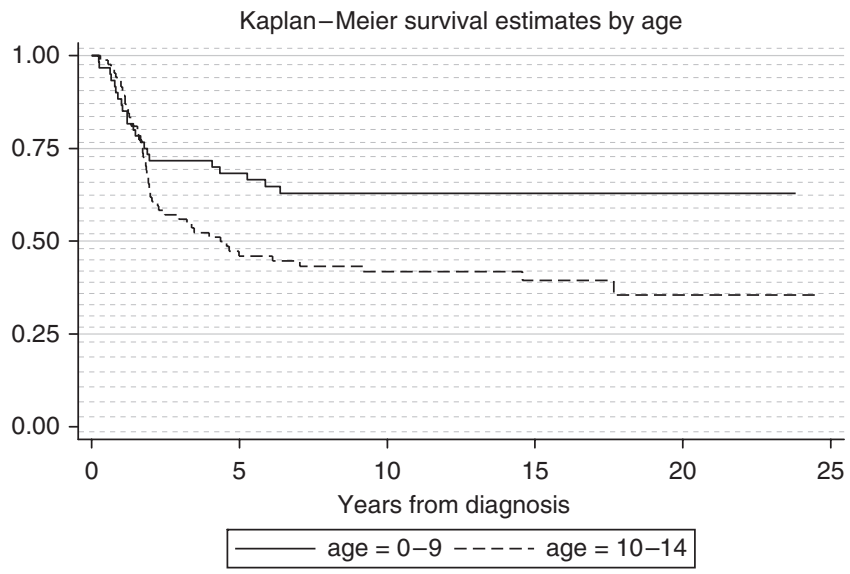

Figure 3 Kaplan-Meier survival for Ewing sarcoma by age. HR (comparing ages $10-14$ years with ages $0-9$ years $)=1.86(95 \% \mathrm{Cl}$ l. $12-3.07 ; P=0.02$ )
Inspection of Schoenfeld residuals showed that all Cox regression models met the assumption of proportional hazards.

\section{DISCUSSION}

This study of childhood bone cancer in $0-14$ year olds in northern England and the West Midlands during the period 1981-2002 found an improvement in survival for Ewing sarcoma, but not for osteosarcoma.

The overall incidence rate was 4.84 per million, similar to that reported worldwide in countries with predominantly white populations (Parkin et al, 1998; Stiller et al, 2006a). Bone tumours in this age group have been previously reported to occur in the United Kingdom at an incidence rate of 5 per million (Stiller, 2007). In addition, the increasing preponderance with age, the equal occurrence of male and female cases in the ages $0-14$ years and the predominance of osteosarcoma and Ewing sarcoma found in this study are also typical patterns reported in earlier studies (Parkin et al, 1998; Stiller et al, 2006a).

Incidence rates were highest at ages 10-14 years. This is consistent with previous literature, as it has been widely reported that incidence of malignant bone tumours peak during the time of puberty (with the peak occurring later in boys than in girls), when children are undergoing a growth spurt and bones experience rapid growth (Grovas et al, 1997; Martin et al, 1997; Stiller et al, 2006a).

Whereas no significant temporal change was found in the incidence of childhood osteosarcoma, chondrosarcoma, other specified or other unspecified bone tumours over the study period, there was a decrease in the incidence of Ewing sarcoma. Several recently published studies have reported that bone tumour incidence remains stable over time in spite of an overall increase in cases of childhood cancer (McNally et al, 2001; Stiller et al, 2006a; Magnanti et al, 2008), with one specifically reporting stable incidence of Ewing sarcoma for the time period 1973-2004 (Esiashvili et al, 2008). Our observed decrease in the incidence of Ewing sarcoma remains unexplained. Although this decrease may be real, the role of artefact cannot be excluded. In three of the four registries (NRYPMDR, YSRCCYP, WMRCTR), there were increases in the incidence of soft-tissue Ewing sarcoma/pPNET 
during the study period. Some tumours previously classified as Ewing may now be classified as soft tissue sarcoma.

Overall, $57.8 \%$ of cases survived for at least 5 years, osteosarcoma (58.8\%) and Ewing sarcoma (54.9\%). This is slightly lower than a recent large Europe-wide study using data from the Automated Childhood Cancer Information System project, which reported the 5-year survival rate as $61 \%$ for malignant bone tumours in children aged 0-14 years in Europe during 1988-1997, with 5-year survival of 59\% for osteosarcoma and $62 \%$ for Ewing sarcoma (Stiller et al, 2006a). Our results are also lower than those reported in the EUROCARE-3 study analysis, which reported $66 \%$ 5 -year survival for osteosarcoma and $69 \%$ for Ewing sarcoma during the time period 1990-1994 (Gatta et al, 2003). However, our results are in line with data from an earlier EUROCARE study, which reported 5-year survival for malignant bone tumours in children aged 0-14 years in England and Wales to be 43 and $45 \%$ for osteosarcoma and Ewing sarcoma, respectively, for 1978-1989, and 55 and 57\% for $1985-1989$ (Stiller et al, 2001). Poorer survival rates may be due to failure to improve accrual into trials.

Our data show that survival from bone tumours in northern England and the West Midlands is lower than that seen in other European countries. Survival data comparing European regions show northern England and the West Midlands to have lower 5 -year survival than the northern, southern and western regions of Europe, with these reporting 66, 65 and 66\% 5-year survival, respectively. Only eastern Europe, which has a $41 \%$ 5-year survival rate, performs worse than northern England and the West Midlands (Stiller et al, 2006a). Variations between countries may reflect differing treatment strategies.

Five-year survival from malignant bone tumours was lower in children in the older age group of 10-14 years than those under the age of 10 years. Lower survival in older age groups has been reported in several studies. However, these tended to compare survival in adolescents aged 15-19 years with children aged 0-14 years (Stiller et al, 2006a, b). No significant survival differences by age were observed in both a recent UK based study analysing data from the National Registry of Childhood Tumours (Stiller, 2007) and in a US study analysing SEER data (Ries et al, 1999). However, our data support another US study of Ewing sarcoma, which reports better survival below the age of 10 years than at ages $10-19$ years (Esiashvili et al, 2008).

Gender was not significant in relation to survival for osteosarcoma or Ewing sarcoma, as reported for Ewing sarcoma in the United Kingdom (Stiller et al, 2006c). However, a recent study of Ewing sarcoma from the United States of America has reported a higher 5-year survival rate in females than males (Esiashvili et al, 2008). In addition, higher survival rates for osteosarcoma have been reported in females than males in a few studies. This difference between genders observed in some studies (Scranton et al, 1975; Homa et al, 1991) may be due to poor response to chemotherapy among males (Bielack et al, 2002).

Survival for Ewing sarcoma increased over the time period 1981-2002, whereas survival for osteosarcoma and the other subgroups remained unchanged. Studies reporting increased survival in both Ewing sarcoma and osteosarcoma over time (Miller et al, 1995; Dama et al, 2006; Stiller et al, 2006a) were concerned with earlier time periods. The most recent study of

\section{REFERENCES}

Ajiki W, Hanai A, Tsukuma H, Hiyama T, Fujimoto I (1994) Incidence of childhood cancer in Osaka, Japan, 1971-1988: reclassification of registered cases by Birch's scheme using information on clinical diagnosis, histology and primary site. Jpn J Cancer Res 85: 139-146

Arndt V, Lacour B, Steliarova-Foucher E, Spix C, Znaor A, Pastore G, Stiller C, Brenner H (2007) Up-to-date monitoring of childhood cancer survival trends in Ewing sarcoma reported an improvement over a 30-year period up until 2004 (Esiashvili et al, 2008). The late 1970s and early 1980s saw the introduction of chemotherapy into the treatment of childhood bone tumours in addition to local control through surgery and radiotherapy. This gave rise to an increase in survival from the disease in this time period (Stiller et al, 2006a). Treatment for childhood bone tumours has not markedly changed since the 1980s, which may explain the subsequent hiatus in survival improvement. However, the lack of progress in achieving improved survival is of concern and requires further investigation and intervention measures. The possible contribution of delay in diagnosis to the lack of improved survival for osteosarcoma should be recognised, as it has been confirmed that long diagnosis delays in bone tumours are common. These long symptom durations are due to both patients and health professionals. Several factors may influence diagnosis delays, for example, delays may be greater for those living in rural compared with urban areas (Schnurr et al, 2008), while the site and biology of the tumour may also determine the extent of delay. Ewing sarcoma patients are more likely to have a longer symptom interval than osteosarcoma due to its greater propensity for growth in the axial skeleton. Early diagnosis and treatment are necessary for securing a favourable outcome (Bielack et al, 2002).

The efficacy of UK treatment regimens also needs investigation. Despite the increase in survival for Ewing sarcoma, the United Kingdom still lags behind Europe, and one contributing factor may be due to the differing treatment in the United Kingdom. This issue has been studied in a comparative survival analysis between the United Kingdom and Germany, where lower overall 5-year survival rates were observed in UK patients compared with those treated in Germany. Local therapy practice appeared to be the only explanatory factor associated with this difference in survival. For example, a higher proportion of German patients were treated with combined radiotherapy and surgery, reflecting a more aggressive philosophy of treatment than in the United Kingdom (Lewis, 2006). A similar change in UK practice may therefore result in increased 5-year survival, reducing the gap in survival with the rest of Europe.

This study highlights the worse survival from bone tumours overall than in other western European countries, and that, in spite of a significant increase in survival from Ewing sarcoma, there has been no such improvement since 1981 from osteosarcoma.

\section{ACKNOWLEDGEMENTS}

We thank all colleagues from The Northern Region Young Persons' Malignant Disease Registry (NRYPMDR), the Yorkshire Specialist Register of Cancer in Children and Young People (YSRCCYP), the West Midlands Regional Children's Tumour Registry (WMRCTR) and the Manchester Children's Tumour Registry (MCTR) for providing patient data. We thank the following for financial support: The Bone Cancer Research Trust (RE, EM), Candlelighters Trust (RF), Cancer Research UK (JB), Teenage Cancer Trust (TE) and the North of England Children's Cancer Research Fund (PJ, RE). long- term survival in Europe: tumours of the sympathetic nervous system, retinoblastoma, renal and bone tumours, and soft tissue sarcomas. Ann Oncol 18: 1722-1733, doi:10.1093/annonc/mdm189

Bielack SS, Kempf-Bielack B, Delling G, Exner GU, Flege S, Helmke K, Kotz R, Salzer-Kuntschik M, Werner M, Winkelmann W, Zoubek A, Jurgens H, Winkler K (2002) Prognostic factors in high grade 
osteosarcoma of the extremities or trunk: an analysis of 1702 patients treated on neoadjuvant cooperative osteosarcoma study group protocols. $J$ Clin Oncol 20: 776-790

Birch JM (1988) Manchester Children's Tumour Registry. In International Incidence of Childhood Cancer, Parkin DM, Stiller CA, Draper GJ, Bieber CA, Terracini B, Young JL (eds). pp 299-304. IARC (IARC Scientific Publications No 87): Lyon

Cotterill SJ, Parker L, Malcolm AJ, Reid M, More L, Craft AW (2000) Incidence and survival for cancer in children and young adults in the North of England, 1968 - 1995: a report from the Northern Region Young Persons' Malignant Disease Registry. Br J Cancer 83: 397-403, doi:10.1054/bjoc. 2000.1313

Dama E, Pastore G, Mosso ML, Maule MM, Zuccolo L, Magnani C, Merletti F (2006) Time trends and prognostic factors for survival from childhood cancer: a report from the Childhood Cancer Registry of Piedmond (Italy). Eur J Pediatr 165: 240 - 249, doi:10.1007/s00431-005-0034-7

Esiashvili N, Goodman M, Marcus RB (2008) Changes in incidence and survival of Ewing sarcoma patients over the past 3 decades: Surveillance Epidemiology and End Results data. J Pediatr Hematol Oncol 30: 425-430

Feltbower RG, Kinsey SE, Richards M, Shenton G, Michelagnoli MP, McKinney PA (2007) Survival following relapse in childhood haematological malignancies diagnosed in 1974-2003 in Yorkshire, UK. Br J Cancer 96: 1147-1152, doi:10.1038/sj.bjc.6603667

Gatta G, Corazziari I, Magnani C, Peris-Bonet R, Roazzi P, Stiller C, for the EUROCARE Working Group (2003) Childhood cancer survival in Europe. Ann Oncol 14(Suppl 5): 119-127, doi:10.1093/annonc/mdg755

Grovas A, Fremgen A, Rauck A, Ruymann FB, Hutchinson CL, Winchester DP, Menck HR (1997) The National Cancer Data Base report on patterns of childhood cancers in the United States. Cancer 80: 2321-2332, doi:10.1002/(SICI)1097-0142(19971215)80:12 < 2321::AID-CNCR14>3.0.CO;2-W

Gurney JG, Davis S, Severson RK, Fang JY, Ross JA, Robison LL (1996) Trends in cancer incidence among children in the US. Cancer 78: 532-541

Homa DM, Sowers MR, Schwartz AG (1991) Incidence and survival rates of children and young adults with osteogenic sarcoma. Cancer 67: 2219-2223

Kaplan EL, Meier P (1958) Non-parametric estimation from incomplete observations. J Am Stat Assoc 53: 457-481

Lewis I (2006) EICESS-92: A Successful Collaborative Intergroup Trial in Ewing's Sarcoma with Unexpected Results. National Cancer Research Institute conference: Birmingham, 8-11 October 2006 [Abstract]

Magnanti BL, Dorak MT, Parker L, Craft AW, James PW, McNally RJ (2008) Sex-specific incidence and temporal trends in solid tumours in young people from Northern England, 1968-2005. BMC Cancer 8: 89, doi: 10.1186/1471-2407-8-89

Martin AA, Alert JA, Reno JS, Lonchong M, Grueiro S (1997) Incidence of childhood cancer in Cuba (1986-1990). Int J Cancer 72: 551-555, doi:10.1002/(SICI)1097-0215(19970807)72:4 < 551::AID-IJC1 > 3.0.CO;2-P

McNally RJ, Kelsey AM, Cairns DP, Taylor GM, Eden OB, Birch JM (2001) Temporal increases in the incidence of childhood solid tumors seen in
Northwest England (1954-1998) are likely to be real. Cancer 92: 1967 - 1976, doi:10.1002/1097-0142(20011001)92:7 < 1967::AID-CNCR1716> 3.0.CO;2-\#

Miller RW, Young JL, Novakovic B (1995) Childhood cancer. Cancer 75(1 Suppl): 395-405

Muir KR, Parkes SE, Mann JR, Stevens MC, Cameron AH (1992) Childhood cancer in the West Midlands: incidence and survival 1980-1984, in a multi-ethnic population. Clin Oncol ( $R$ Coll Radiol) 4: 177-182

Parkin DM, Stiller CA, Draper GJ, Bieber CA, Terracini B, Young JL (eds). (1998) International Incidence Of Childhood Cancer, Vol 2, IARC (IARC Scientific Publications No 87): Lyon

Ries LAG, Smith MA, Gurney JG, Linet M, Tamra T, Young JL, Bunin GR (eds). (1999) Cancer Incidence and Survival among Children and Adolescents: United States SEER Program 1975-1995. National Cancer Institute (SEER Program. NIH Pub. No. 99-4649): Bethesda, MD

Schnurr C, Pippan M, Stuetzer H, Delank KS, Michael JW, Eysel P (2008) Treatment delay of bone tumours, compilation of a sociodemographic risk profile: a retrospective study. BMC Cancer 8: 22, doi:10.1186/ 1471-2407-8-22

Scranton PE, DeCicco FA, Totten RS, Yunis EJ (1975) Prognostic factors in osteosarcoma. A review of 20 years' experience at the University of Pittsburgh Health Center Hospitals. Cancer 36: 2179-2191

Smith PG (1992) Comparison between registries: age-standardized rates. In Cancer Incidence in Five Continents, Parkin DM, Muir CS, Whelan SL, Gao Y-T, Ferlay J, Powell J (eds)., Vol. VI, IARC (IARC Scientific Publications No 120): Lyon

Steliarova-Foucher E, Stiller C, Lacour B, Kaatsch P (2005) International Classification of Childhood Cancer, third edition. Cancer 103: 1457 - 1467, doi:10.1002/cncr.20910

Stiller CA, Craft AW, Corazziari I, EUROCARE Working Group (2001) Survival of children with bone sarcoma in Europe since 1978: results from the EUROCARE study. Eur J Cancer 37: 760-766, doi:10.1016/ S0959-8049(01)00004-1

Stiller CA, Bielack SS, Jundt G, Steliarova-Foucher E (2006a) Bone tumours in European children and adolescents, 1978-1997. Report from the Automated Childhood Cancer Information System project. Eur J Cancer 42: $2124-2135$, doi:10.1016/j.ejca.2006.05.015

Stiller CA, Desandes E, Danon SE, Izarzugaza I, Ratiu A, VassilevaValerianova Z, Steliarova-Foucher E (2006b) Cancer incidence and survival in European adolescents (1978-1997). Report from the Automated Childhood Cancer Information System project. Eur J Cancer 42: 2006 -2018, doi:10.1016/j.ejca.2006.06.002

Stiller CA, Passmore SJ, Kroll ME, Brownbill PA, Wallis JC, Craft AW (2006c) Patterns of care and survival for patients aged under 40 years with bone sarcoma in Britain, 1980-1994. Br J Cancer 94: 22-29, doi:10.1038/sj.bjc.6602885

Stiller CA (ed.) (2007) Childhood Cancer in Britain: Incidence, Survival, Mortality. Oxford University Press: Oxford 